\title{
A NEW SPECIES OF THE GENUS HALOLAELAPS BERLESE \& TROUESSART, 1889 (ACARI, GAMASIDA, HALOLAELAPIDAE) FROM THE SPANISH MEDITERRANEAN COAST
}

\author{
C. Blaszak (*) \& R. Ehrnsberger (**)
}

\begin{abstract}
The new species Halolaelaps (Saprogamasellus) hispanicus sp. nov. of Halolaelapidae mites (Acari, Gamasida) is described and determination keys to the males and females of the subgenus Saprogamasellus are given.

Key words: Halolaelaps hispanicus sp. nov., Halolaelapidae, Mediterranean coast, Spain.
\end{abstract}

\section{RESUMEN}

Nueva especie del género Halolaelaps Berlese \& Trouessart, 1889 (Acari, Gamasida, Halolaelapidae) de la costa mediterránea española

Se describe una nueva especie de ácaro de la familia Halolaelapidae, Halolaelaps (Saprogamasellus) hispanicus sp. nov., y se proporcionan claves de identificación de machos y hembras del subgénero Saprogamasellus.

Palabras clave: Halolaelaps hispanicus sp. nov., Halolaelapidae, Mediterráneo, España.

Until today the following Halolaelaps (Saprogamasellus)-species are known from the Mediterranean coast: $H$. (S.) albertii Blaszak \& Ehrnsberger, 1993; H. (S.) caesariensis AthiasHenriot, 1961 and $H$. (S.) similis Blaszak \& Ehrnsberger, 1993. From the North Sea are reported 11 species (Blaszak \& Ehnrsberger, 1993). Examining mesostigmatic mites from the marine littoral, we found a new species belonging to the genus Halolaelaps Berlese \& Trouessart, 1889. On the basis of the present division of this genus (Blaszak \& Ehrnsberger, 1995) the new species belongs to the subgenus Saprogamasellus Sellnick, 1957; it is characterised by the following peculiarities:
1. Genu III in adults and deutonymphs with 9 setae (genus criterion)

2. Tectum with 3 tips, the tip in the middle is furcated and always a little bit longer, the lateral tips are serrated

3. Coxa II anterior without spur

4. Femur I with 12 setae

5. Males with sternogenital shield (genus criterion).

\section{Halolaelaps (Saprogamasellus) hispanicus sp. nov.}

Material: Mediterranean Sea: Spain, Valencia - 1 female (holotype), 1 male (paratype). Tide-washed seashore area with

\footnotetext{
* Department of Animal Morphology, Institute of Environmental Biology /Poland, Adam Mickiewicz University Poznañ, Szamarzewskiego 91,60-569 Poznañ, Poland. e-mail: blaszak@hum.amu.edu.pl

** Institute of Nature Conservation and Environmental Education, University of Vechta, D-49364 Vechta, Postbox 1553 , Germany. e-mail: rainer.ehrnsberger@uni-vechta.de
} 


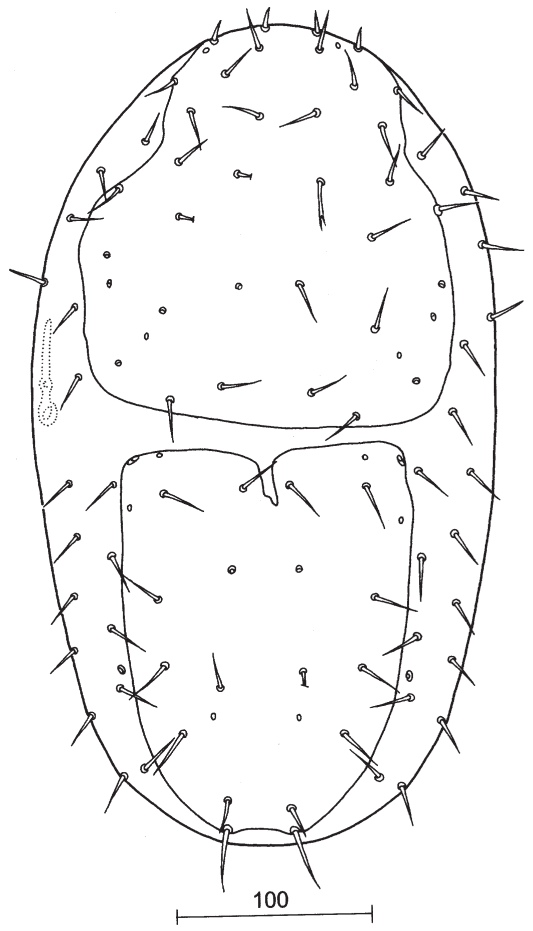

Fig. 1.- Halolaelaps (Saprogamasellus) hispanicus sp. nov. Female, dorsal side

Fig. 1.- Halolaelaps (Saprogamasellus) hispanicus sp. nov. Hembra, vista dorsal.

lot of brown algae (Fucus), 20.09.1989, leg. Rainer Ehrnsberger. TYPES: The holotype is situated in the Zoological Museum of the University of Hamburg, Germany; the paratype is in the Department of Animal Morphology of the Adam Mickiewicz University of Poznañ, Poland.

Female (Fig. 1): Holotype. Length $420 \mu \mathrm{m}$, podonotal shield $200 \mu \mathrm{m}$, opisthonotal shield 200 $\mu \mathrm{m}$. Podonotal shield with 17 pairs of setae, setae of r2-r6-rows are not positioned on the shield; setae s3 at the rim of the opisthonotum; opisthonotal shield with 9 pairs of setae, setae Z5 approximately twice longer than I5, setae Z5 on the shield; setae of Rand S-rows not on the shield, median incision on opisthonotal shield deep, extending beyond the base of setae I1; peritrema short, maximal to the middle of Coxa III. Tectum with 3 tips, the tip in the middle furcated and always a little bit longer, lateral tips serrated (Fig. 4c).

MALE: Paratype. Length $340 \mu \mathrm{m}$, podonotal shield $200 \mu \mathrm{m}$, opisthonotal shield $150 \mu \mathrm{m}$.

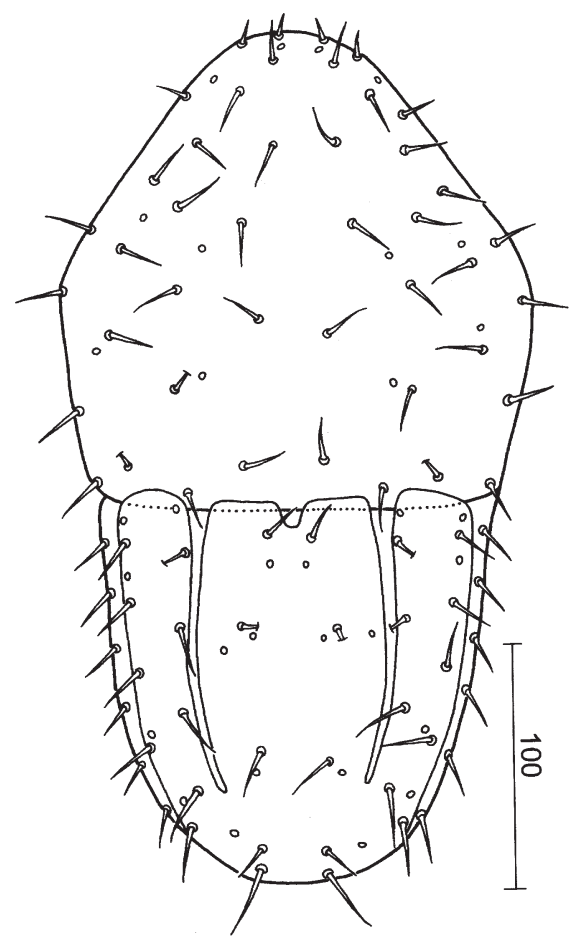

Fig. 2.- Halolaelaps (Saprogamasellus) hispanicus sp. nov. Male, dorsal side

Fig. 2.- Halolaelaps (Saprogamasellus) hispanicus sp. nov. Macho, vista dorsal.

Dorsal SIDE (Fig. 2): Podonotal shield with 22 pairs of setae; opisthonotal shield with 14 pairs of setae. All setae of R-rows not on the shield. Setae Z5 at least twice longer than I5; I5 shortest setae on opisthonotum; median incision in opisthonotal shield not deep, not reaching to the base of I1; opisthonotal shield with two additionally lateral deep incisions, reaching to setae Z4.

VENTRAL SIDE (Fig. 3): Ventroanal shield with 9 pairs of setae and single postanal seta. The adanal setae are very long, reaching to the end of the opisthosoma. In the anterior part of this shield, two small thick clasps of chitin are situated; between sternogenital and ventroanal shield one small shield. Peritrema short, reaching to the middle of Coxa III.

LEGS (Fig. 4): Genu III with 6 knots, tibia III with 6 knots, tarsus III with 2 knots and 1 apophysis. Genu IV with 4 knots, tibia IV with 6 knots, tarsus IV with 2 knots and 1 apophysis. 


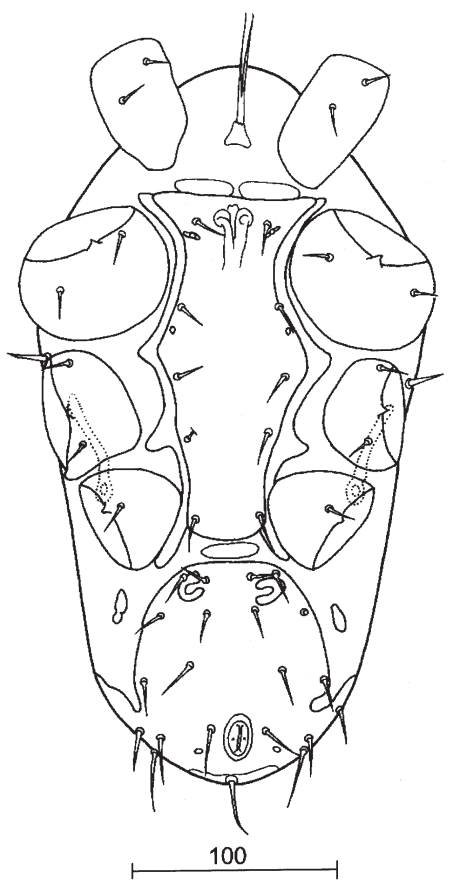

Fig. 3.- Halolaelaps (Saprogamasellus) hispanicus sp. nov. Male, ventral side

Fig. 3.- Halolaelaps (Saprogamasellus) hispanicus sp. nov. Macho, vista ventral.

DiFFERENTIAL DIAGNOSIS: The new species belongs to the "strenzkei"-group, with 9 pairs of setae on the opisthonotal shield (see Table 1).

ETymology: The name of the new species Halolaelaps (Saprogamasellus) hispanicus was derived from the name of the country where it was found.

Determination key to the males of the subgenus Halolaelaps (Saprogamasellus) Sellnick, 1957

1. Without clasps of chitin on the anterior part of the ventroanal shield .. H. (S.) similis Blaszak \& Ehrnsberger, 1993

* With 1 or 2 clasps of chitin on the anterior part of the ventroanal shield

2. With 1 clasp of chitin on the anterior part of the ventroanal shield

* With 2 clasps of chitin on the anterior part of the ventroanal shield

3. Opisthonotal shield with lateral lacunes. Genu IV with 4 knots H. (S.) nodosus Willmann, 1952
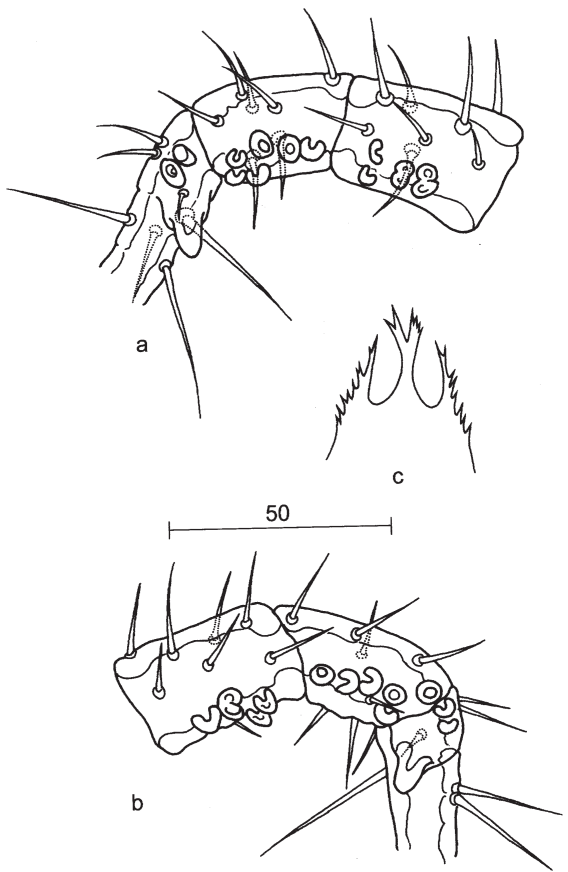

Fig. 4.- Halolaelaps (Saprogamasellus) hispanicus sp. nov. a) Leg III male: genu, tibia, tarsus; b) Leg IV male: genu, tibia, tarsus; c) Tectum of female

Fig. 4.- Halolaelaps (Saprogamasellus) hispanicus sp. nov. a) Pata III del macho: genu, tibia, tarso; b) Pata IV del macho: genu, tibia, tarso; c) Tectum de la hembra.

* Opisthonotal shield with lateral incisions. Genu IV with 5 knots .... H. (S.) nodosoides Blaszak \& Ehrnsberger, 1993

4. Opisthonotal shield without lateral incisions or lacunes (only with anterior single incision)

H. (S.) obtusus Blaszak \& Ehrnsberger, 1993

* Opisthonotal shield with lateral incisions or lacunes ...... 5

5. Opisthonotal shield with lateral lacunes ……….............. 6

* Opisthonotal shield with lateral incisions ........................... 9

6. Tibia IV with 7 knots ........ H. (S.) coxalis Sellnick, 1957

* Tibia IV with 6 or 5 knots ......................................... 7

7. Tibia IV with 6 knots ............ H. (S.) incisus Hyatt, 1956

* Tibia IV with 5 knots .................................................... 8

8. Tarsus IV with 3 knots .. H. (S.) strenzkei Sellnick, 1957

* Tarsus IV without knots ... H. (S.) simplex Sellnick, 1957

9. Tibia IV with 6 knots ................ H. (S.) hispanicus sp. n.

* Tibia IV with 5 knots or less .................................... 10

10. Tibia IV with 5 knots ...................................................... 11

* Tibia IV with 4 or less knots ........................................ 13

11. Tarsus IV with 2 knots .. H. (S.) remanei Willmann, 1939

* Tarsus IV with 1 knots ............................................. 12

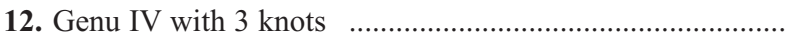
H. (S.) albertii Blaszak \& Ehrnsberger, 1993

* Genu IV without knots .... H. (S.) suecicus Sellnick, 1957

13. Tibia IV with 4 knots ................................................ 14

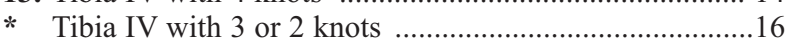


Table 1.- Differential diagnosis of Haloaelaps (Saprogamasellus) hispanicus.

Table 1.- Diagnosis diferencial de Haloaelaps (Saprogamasellus) hispanicus.

FEMALES

\begin{tabular}{|c|c|c|}
\hline H. (S.) hispanicus sp. $\mathrm{n}$. & H. (S.) albertii Blaszak \& Ehrnsberger, 1993 & H. (S.) incisus Hyatt, 1956 \\
\hline $\begin{array}{l}\text { Podonotum with } 17 \text { pairs of setae } \\
\text { r1 on podonotum } \\
\text { s3 on podonotum } \\
\text { Opisthonotal shield with } 9 \text { pairs of setae }\end{array}$ & $\begin{array}{l}\text { Podonotum with } 15 \text { pairs of setae } \\
\text { r1 not on podonotum } \\
\text { s3 on podonotum }\end{array}$ & $\begin{array}{l}\text { Podonotum with } 16 \text { pairs of setae } \\
\text { r1 not on podonotum } \\
\text { Opisthonotal shield with } 8 \text { pairs of setae }\end{array}$ \\
\hline
\end{tabular}

MALES

\begin{tabular}{lll}
\hline H. (S.) hispanicus sp. n. & H. (S.) albertii Blaszak \& Ehrnsberger, 1993 & H. (S.) incisus Hyatt, 1956 \\
\hline Genu IV with 4 knots & Genu IV with 3 knots & Genu IV without knots \\
Tarsus IV with 2 knots & Tarsus IV with 1 knots & Tarsus IV with 3 knots \\
Tibia IV with 6 knots & Tibia IV with 5 knots & Opisthonotal shield with 2 lateral lacunas \\
Opisthonotal shield with lateral incisions & & \\
\hline
\end{tabular}

14. Tarsus IV with 2 knots

H. (S.) balticus Sellnick, 1957

* Tarsus IV with 1 knots

15. Opisthonotal setae Z5 always needle like and sharp

H. (S.) sinuosus Blaszak \& Ehrnsberger, 1993

* Opisthonotal setae Z5 always blunt

H. (S.) caesariensis Athias-Henriot, 1961

16. Tibia IV with 3 knots, Tarsus IV with 1 knots

H. (S.) rafalskii Blaszak \& Ehrnsberger, 1993

* Tibia IV with 2 knots, Tarsus IV without knots

H. (S.) reinharti Blaszak \& Ehrnsberger, 1993

\section{Determination key to the females of the subgenus Halolaelaps (Saprogamasellus) Sellnick, 1957}

1. Opisthonotal shield with 14 pairs of setae 2

* Opisthonotal shield with less setae ………..................... 3

2. Peritrema very long (nearly to the anterior rim of Coxa I) H. (S.) nodosus Willmann, 1952

* Peritrema short (never to the anterior rim of Coxa II) ..... H. (S.) silveae Blaszak \& Ehrnsberger, 1993

3. Opisthonotal shield with 13 pairs of setae H. $(\boldsymbol{S}$.$) nodosoides Blaszak \& Ehrnsberger, 1993$

* Opisthonotum with less setae

4. Opisthonotal shield with 11 pairs of setae

$H$. $(S)$ suecicus Sellnick, 1957

* Opisthonotal shield with 10 pairs of setae or less .......... 5

5. Opisthonotal shield wit 10 pairs of setae ......................... 6

* Opisthonotal shield with less setae .................................. 7

6. Setae S4 not on the opisthonotal shield, setae S5 on the shield .................................. H. (S.) coxalis Sellnick, 1957

* Setae S4 on opisthonotal shield, setae S5 not on the shield H. (S.) propinquus Blaszak \& Ehrnsberger, 1993

7. Opisthonotal shield with 9 pairs of setae
* Opisthonotal shield with 8 pairs of setae 11

8. Setae i1 on the podonotal shield ................................... 9

* Setae i1 not on the podonotal shield ............................ 10

9. Setae $\mathrm{r} 1$ on the podonotal shield; podonotal shield with 17 pairs of setae ....................... H. (S.) hispanicus sp. nov.

* Setae $r 1$ not on the podonotal shield; podonotal shield with 15 pairs of setae

H. (S.) albertii Blaszak \& Ehrnsberger, 1993

10. Setae z1 not on the podonotal shield ..................................

Setae z1 on the podonotal shield

H. (S.) strenzkei Sellnick, 1957

11. Tarsus IV with apophysis!

H. (S.) simplex Sellnick, 1957

................................... H. (S.) remanei Willmann, 1939

* Tarsus IV without apophysis ....................................... 12

12. Opisthonotal shield with whip like setae, setae $Z 5$ at least 2,5 times longer than I5 ........ H. (S.) incisus Hyatt, 1956

* Opisthonotal shield with needle like or blunt setae, setae Z5 maximal twice as long as I5 (regularly 1,5 times) .. 13

13. Podonotal shield with 17 pairs of setae (setae i1, z1 and $\mathrm{r} 1$ on podonotal shield)

H. $(\boldsymbol{S}$.$) caesariensis Athias-Henriot, 1961$

* Podonotal shield with 16 or 15 pairs of setae .............. 14

14. Podonotal shield with 15 pairs of setae (setae i1 and r1 not on podonotal shield)

H. (S.) rafalskii Blaszak \& Ehrnsberger, 1993

* Podonotal shield with 16 pairs of setae ........................ 15

15. All setae on opisthonotal shield (also on podonotal shield) blunt .......... H. (S.) obtusus Blaszak \& Ehrnsberger, 1993

* A lot of setae on opisthonotal shield needle-like (setae I1 always acute) (.............................................................. 16

16. Median incision on opisthonotal shield very broad and only reaching to the base of setae I1

H. (S.) similis Blaszak \& Ehrnsberger, 1993

* Median incision on opisthonotal shield normally narrow and always reaching to the end of setae I1

17 
17. Setae il on podonotal shield, setae $\mathrm{r} 1$ not on podonotal shield H. (S.) balticus Sellnick, 1957

* Setae i1 not on podonotal shield, setae r1 on podonotal shield ...... H. (S.) sinuosus Blaszak \& Ehrnsberger, 1993

\section{References}

Athias-Henriot, C., 1961. Mesostigmates (Urop. excl.) Edaphiques Mediterraneens (Acaromorpha, Anactinotrichida). Acarologia, 3(4): 381-509.

Blaszak, C. \& Ehrnsberger, R., 1993. Beiträge zur Kenntnis von Halolaelaps (Saprogamasellus) Götz, 1952 (Acari: Gamasida: Halolaelapidae). Genus, 4(3): 143-267.
BlaszaK, C. \& Ehrnsberger, R., 1995. Beiträge zur Kenntnis von Halolaelaps (Halogamasellus) subgen. nov., (Acari: Gamasida: Halolaelapidae). Osnabrücker Naturwissenschaftliche Mitteilungen, 20/21: 25-94.
Recibido, el 22-I-1998 Aceptado, el 17-III-1999 Publicado, el 15-XII-1999 